Available online on 15.06 .2020 at http://jddtonline.info
Open Access to Pharmaceutical and Medical Research
unrestricted non-commercial use, provided the original work is properly cited

Open $\odot$ Access

Research Article

\title{
Formulation of Ramipril Tablets Containing Solid Dispersion Employing Selective Polymers to Enhance Dissolution Rate
}

\author{
Inder Kumar*, Sandeep Verma, Amit Chaudhary \\ School of Pharmacy, Abhilashi University, Chailchowk, Mandi, India
}

\begin{abstract}
Objective: The present work based on formulation of Ramipril tablets containing solid dispersion employing selective polymers. The objective of the preparation is to prepare the solid dispersion of the Ramipril, which has more responsive value in terms of the dissolution rate.

Method: Solid dispersion complex was prepared with two different carriers PEG 6000 and PVP K30. Nine formulations were developed and each formulation were subjected to pre compression and post compression parameters.

Result and Discussion: Pre-compression and post compression parameters were studied which had shown good flow property and compiled the standard data. In-vitro dissolution studies shows more than $90 \%$ drug release in phosphate buffer pH 6.8 in 30 min. Out of all formulation F4 showed $92.55 \pm 0.67 \%$ drug release with in $30 \mathrm{~min}$ which was the best result rest of the formulation.

Conclusion: Ramipril tablets were successfully prepared and evaluated. F4 formulation shows the greater dissolution rate in phosphate buffer pH 6.8 as compared to other formulations. When compared with marketed formulation it also shows better results. Therefore, Ramipril solid dispersion tablets enhanced the dissolution rate and can be more efficacious for improving oral bioavailability of Ramipril.
\end{abstract}

Keywords: Solid dispersion, Ramipril, Solvent Evaporation Technique.

Article Info: Received 22 March 2020; Review Completed 19 May 2020; Accepted 06 June 2020; Available online 15 June 2020

Cite this article as:

Kumar I, Verma S, Chaudhary A, Formulation of Ramipril Tablets Containing Solid Dispersion Employing Selective Polymers to Enhance Dissolution Rate, Journal of Drug Delivery and Therapeutics. 2020; $10(3-s): 142-149$ http://dx.doi.org/10.22270/jddt.v10i3-s.4109

*Address for Correspondence:

Inder Kumar, School of Pharmacy, Abhilashi University, Chailchowk, Mandi, India

\section{INTRODUCTION}

One of the foremost difficult aspects pharmaceutical industries have long-faced is to boost the oral bioavailability of the poorly soluble medication. On an average $30-40 \%$ of newly discovered drug, candidates are poor water-soluble hence, it becomes necessary to enhance the solubility of the poorly water-soluble drugs. ${ }^{1,2}$

Ramipril is an inhibitor of angiotensin converting enzyme and it is a pro drug. Liver is responsible for converting Ramipril to the Ramiprilet and in a less extent converted in kidneys. ACE is accountable for converting ATI to ATII and Ramiprilat is a potent and effective inhibitor of ACE. Angiotensin II is the key constituent of RAAS and it regulates blood pressure. For the treatment of hypertension, congestive heart failure and nephropathy, Ramipril is found to be useful. 3,4

Ramipril hinders the RAAS system by binding to and inhibiting ACE thereby preventing the conversion of angiotensin I to angiotensin II. Angiotensin 1 receptor mediates vasoconstriction, inflammation, fibrosis, and oxidative stress through a variety of signaling pathways. As plasma levels of angiotensin II fall, less activation of the Gprotein coupled receptors angiotensin receptor I and angiotensin receptor II occurs. Angiotensin includes actions such as $G_{q}$ coupling to the inositol tri-phosphate pathway, activation of phospholipases $\mathrm{C}, \mathrm{A}_{2}$, and $\mathrm{D}$ which contribute to eicosanoid production, activation of $\mathrm{Ca}^{2+}$-dependent and MAP kinases, $G_{i}$ and $G_{12 / 13}$, and eventual activation of the Jak/STAT pathway leading to cell growth and production of extracellular matrix components.

$\mathrm{AT}_{2} \mathrm{R}$ acts in opposition to the effects of $\mathrm{AT}_{1} \mathrm{R}$ by activating phosphotyrosine phosphatases, which inhibit MAP kinases, inhibiting $\mathrm{Ca}^{2+}$ channel opening, and stimulating cGMP and nitric oxide production leading to vasodilation.5, 6

According to the Bio pharmaceutics Classification System (BCS), Ramipril is a Class II having low solubility and high permeability. In the Present Study, formulation of Ramipril tablets containing solid dispersion employing selective 
polymers were prepared to enhanced the dissolution rate that will leads to the increased bioavailability.

\section{MATERIALS AND METHODS}

Ramipril was obtained as a gift sample from SGPTC Pvt Ltd. Polymers like, PEG 6000, Cross caramellose sodium (CCS), Crospovidone (CP), Sodium starch glycolate (SSG) were procured from CDH Fine Chemicals New Delhi and all other chemicals were procured from SD Fine-chem. Ltd, Mumbai. The entire chemicals were used of Analytical Grade.

\section{Pre-formulation studies}

All the Preformulation studies like melting point, solubility study, and partition coefficient were carried out effectively. ${ }^{7-}$ 9

\section{Estimation of Ramipril}

\section{Determination of $\lambda$ max of Ramipril}

A $10 \mu \mathrm{g} / \mathrm{ml}$ solution of Ramipril in methanol was scanned in the range of $200-400 \mathrm{~nm} .10$

\section{Preparation of standard curve of Ramipril in methanol}

The standard stock solution of Ramipril $(1 \mathrm{mg} / \mathrm{ml})$ was prepared in methanol. This solution was diluted with methanol, to obtain various dilutions from $2-20 \mu \mathrm{g} / \mathrm{ml}$. Absorbance of these solutions was recorded at $210 \mathrm{~nm}$ against methanol as blank using UV-visible spectrophotometer and standard curve was plotted against concentration. From the calibration curve intercept, slope, straight-line equation and correlation coefficient were obtained.

\section{FTIR of Ramipril and Excipients}

The samples were triturated and mixed well with potassium bromide in the ratio 1:100. Then the mixture was introduced in the sample holder and scanned to obtain the graphs in the range of 4000-400 $\mathrm{cm}^{-1}$. The spectra of pure drug and drug with excipients were compared to check any incompatibility and physical changes. ${ }^{11}$

\section{Preparation of Solid Dispersion}

Freeze drying method was used for the preparation of solid dispersion. Accurately weighed drug, PEG6000, and PVP K30 in $\mathrm{mM}$ ratio of $1: 1 \mathrm{mM}$ was dissolved in $1: 1 \mathrm{mM}$ solution of methanol: water to get a clear solution. Both the solutions were mixed and were stirred for 24 hour at a controlled temperature $\left(40 \pm 1^{\circ} \mathrm{C}\right)$ to remove the organic solvent. The obtained solution was filtered, gradually cooled down to room temperature, and then placed in a refrigerator at $-20^{\circ} \mathrm{C}$. The fully frozen solution was dried in a vacuum freeze dryer, and the resulting solid complexes were collected. 12

\section{Evaluation of Solid Dispersion}

\section{Micromeretic properties}

Micromeretics Properties like Bulk Density, tapped density, angle of repose, Carr's index and hausner ratio were evaluated. 13

\section{Solubility Study of Solid Dispersion Complex}

Excess quantities of pure drug (20 mg) and its inclusion complexes were added to $5 \mathrm{ml}$ of distilled water to obtain supersaturated solutions. The solutions were continuously stirred for $24 \mathrm{~h}$ at $25^{\circ} \mathrm{C}$. After $24 \mathrm{~h}$ each sample was centrifuged at $15000 \mathrm{rpm}$ and supernatant was withdrawal. After that supernatant was filtered and filtrate was suitably diluted and determined spectrophotometrically at $210 \mathrm{~nm}$.

\section{Determination of Drug content}

Drug: PEG6000 complex equivalent to $10 \mathrm{mg}$ of drug was stirred for 60 minutes with $100 \mathrm{ml}$ of methanol, then filtered and handled as $100 \mu \mathrm{g} / \mathrm{ml}$ inventory solution. The level of $10 \mu \mathrm{g} / \mathrm{ml}$ was prepared from this inventory solution and the medication content was determined using the methanol spectrophotometric calibration curve of pure medication at $210 \mathrm{~nm}$ using methanol as void. 14

\section{In-vitro dissolution studies of Solid Dispersion}

Studies of drug release using USP apparatus II at $75 \mathrm{rpm}$ were conducted in triplicate at $37 \pm 0.5^{\circ} \mathrm{C}$. Two dissolution media (Phosphate buffer pH 6.8 and $0.1 \mathrm{~N}(\mathrm{HCl})$ ) were used for the dissolution research. Dissolution studies were performed on pure drug $(10 \mathrm{mg})$ and the complex containing an equivalent amount of the drug. At pre-specified time intervals, $0.25 \mathrm{~min}, 0.5 \mathrm{~min}, 1,2,3,4,5,6,7,8,9,10,12,24$ hrs., samples $(5 \mathrm{ml})$ were extracted and replaced with an equal volume of the same dissolution medium maintained at $37^{\circ} \mathrm{C}$ and were analyzed spectrophotometrically at $210 \mathrm{~nm} .{ }^{14}$

\section{Formulation of Ramipril Solid Dispersion Tablets}

The tablets were prepared in accordance with the formula provided in Table 5 by direct compression technique. All ingredients except magnesium stearate were carried through mesh \#18. Stearate of magnesium was carried through mesh \#22. Solid dispersion equal to $10 \mathrm{mg}$ of drug and superdisintegrants were mixed by taking tiny portions of each in ascending order and blended into a mortar to obtain a uniform combination. The other ingredients were weighed and mixed in geometric order and tablets were compressed using a single punching machine with $8 \mathrm{~mm}$ round flat punches. 15

Table 1: Composition of Ramipril Tablets

\begin{tabular}{|c|c|c|c|c|c|c|c|c|c|}
\hline Ingredients (mg) & F1 & F2 & F3 & F4 & F5 & F6 & F7 & F8 & F9 \\
\hline Drug solid dispersion (equivalent to 10mg) & 26 & 26 & 26 & 26 & 26 & 26 & 26 & 26 & 26 \\
\hline Cross caramellose sodium (CCS) & 8 & 16 & 20 & - & - & - & - & - & - \\
\hline Menthol & 15 & 15 & 15 & 15 & 15 & 15 & 15 & 15 & 15 \\
\hline Sodium starch glycolate (SSG) & - & - & - & - & - & - & 8 & 16 & 20 \\
\hline Micro crystalline cellulose & 132 & 124 & 120 & 132 & 124 & 120 & 132 & 124 & 120 \\
\hline Magnesium stearate & 4 & 4 & 4 & 4 & 4 & 4 & 4 & 4 & 4 \\
\hline Talc & 3 & 3 & 3 & 3 & 3 & 3 & 3 & 3 & 3 \\
\hline Crospovidone (CP) & - & - & - & 8 & 16 & 20 & - & - & - \\
\hline D-sorbitol & 12 & 12 & 12 & 12 & 12 & 12 & 12 & 12 & 12 \\
\hline
\end{tabular}




\section{Evaluation of Tablets}

Pre-compression studies like bulk density, tapped density, angle of repose, Carr's index and Hausner's ration were carried out successfully

\section{Post Compression Studies}

The prepared tablets were evaluated for post compression studies, which are as follows:

\section{Weight variation}

20 tablets were selected randomly from a batch and were individually weighed and then the average weight was calculated. The individual weight was then compared with the average value to find the deviation in weight. 16

\section{Hardness}

The device measures the force needed to break the tablet when it reaches the tablet with the force produced by plungers. The tablet was positioned between two plungers; force was applied to the plungers and the crushing power was registered which only causes the tablet to break. From each formulation, the crushing force test was conducted on 5 tablets. 16

\section{Friability}

Pre-weighed tablets (20) were placed in Roche friabilator and were subjected to 100 revolutions at $25 \mathrm{rpm}$ for 4 minutes at a height of 6 inches. The tablets were de-dusted and reweighed. It is calculated by the formula:

$$
\text { Friability } \%=\frac{\text { Initial weight }- \text { Final weight }}{\text { Initial weight }} \times 100
$$

\section{Thickness}

The tablet thickness was determined using a caliper from Vernier. Five tablets were used and average values were calculated from each formulation type. ${ }^{17}$

\section{In-vitro disintegration time}

Place one tablet in each of the basket's six pipes. Add a disk to each tube and run the device using distilled water as the immersion liquid maintained at $37^{\circ} \pm 2^{\circ} \mathrm{C}$. In the $0.1 \mathrm{~N} \mathrm{HCl}$ maintained at $37^{\circ} \pm 2{ }^{\circ} \mathrm{C}$, the assembly should be raised and lowered between 30 cycles per minute. The time taken in seconds to disintegrate the tablet completely without any palpable mass left in the device was measured and registered. 17

\section{In-vitro dissolution studies}

Using USP type-II devices (50 rpm), using $900 \mathrm{ml}$ of $0.1 \mathrm{~N} \mathrm{HCl}$ and Phosphate Buffer pH 6.8 as a dissolution medium, dissolution rate was researched. The dissolution medium temperature has been maintained at $37 \pm 0.5^{\circ} \mathrm{C}$. At a predetermined time interval $(5,10,15,20,25,30 \mathrm{~min}) 5 \mathrm{ml}$ of the sample was removed and replaced by the fresh medium at every $5 \mathrm{~min}$ interval. The absorption of the filtered solution was assessed at $210 \mathrm{~nm}$ using a UV spectrophotometric technique and the drug concentration was determined from the normal calibration curve. 18

\section{RESULT AND DISCUSSION}

\section{Pre-Formulation}

The selected drug Ramipril was subjected for investigation of physical characterization parameters such as: organoleptic properties, melting point, solubility, partition coefficient and were find with in the acceptance criteria as per IP.

\section{Determination of absorption of Ramipril in methanol}

The absorption maxima of Ramipril were obtained in methanol and it was found $210 \mathrm{~nm}$. Calibration curve obtained from different concentration shows good regression value of 0.9925 .

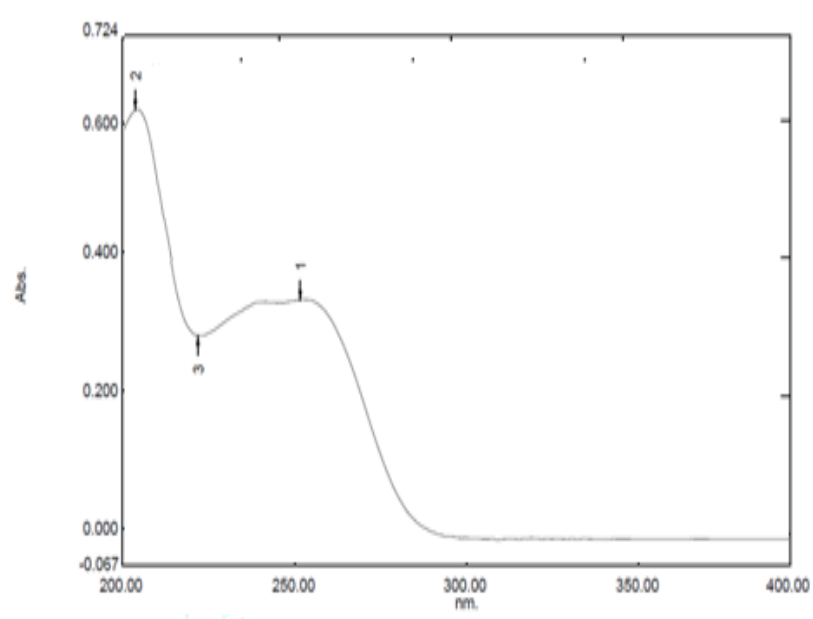

Figure 1: UV Spectrum of Ramipril in methanol

Table 2: Calibration curve of Ramipril in methanol

\begin{tabular}{|c|c|}
\hline Concentration $(\boldsymbol{\mu g} / \mathbf{m l})$ & Absorbance (mean $\mathbf{S D})$ \\
\hline 2 & $0.149 \pm 0.001$ \\
\hline 4 & $0.256 \pm 0.001$ \\
\hline 6 & $0.373 \pm 0.001$ \\
\hline 8 & $0.486 \pm 0.002$ \\
\hline 10 & $0.58 \pm 0.007$ \\
\hline 12 & $0.671 \pm 0.008$ \\
\hline 14 & $0.743 \pm 0.006$ \\
\hline 16 & $0.824 \pm 0.007$ \\
\hline 18 & $0.901 \pm 0.008$ \\
\hline
\end{tabular}

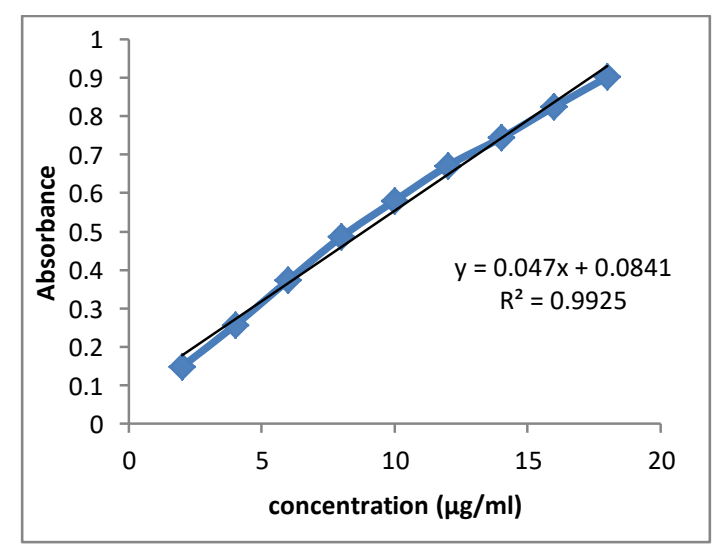

Figure 2: Standard calibration curve of Ramipril in methanol 


\section{FTIR of Ramipril and Excipients}

In case of PEG 6000, the spectrum was characterized by the appearance of broad band at $3383 \mathrm{~cm}^{-1}$ which corresponds to the $\mathrm{OH}$ group. The band at $1232 \mathrm{~cm}^{-1}$ is for $\mathrm{C}-0$ stretching.

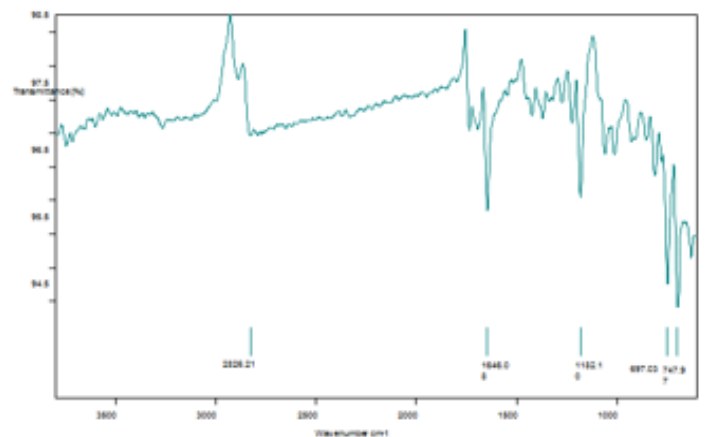

(a)
For the binary SD with PEG 6000, the spectrum is the sum of the spectra of the drug and polymer with the main bands being clear. This suggests absence of any interaction between the drug and PEG 6000 (Figure 3).

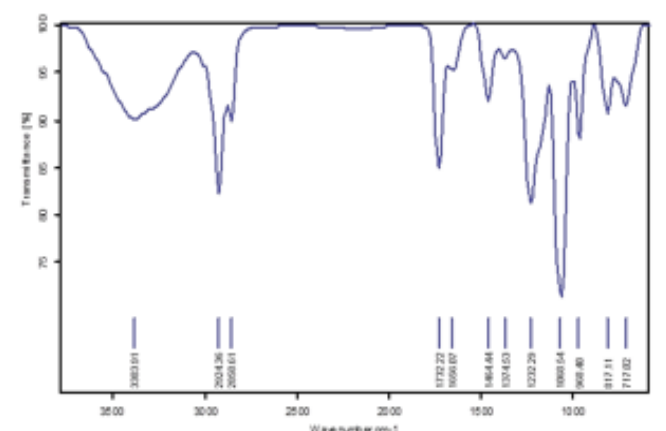

(b)

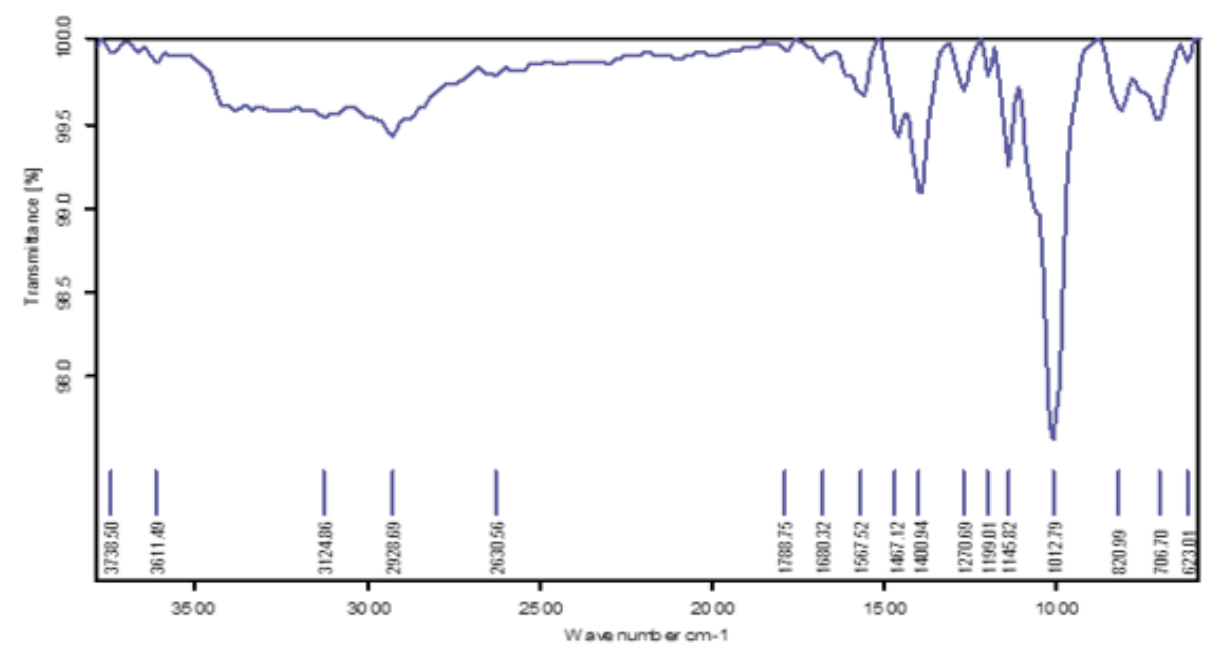

(c)

Figure 3: FTIR Spectrum of (a) pure drug (b) PEG6000 (c) Solid dispersion

\section{Evaluation of solid dispersion}

\section{Micromeretic properties}

After studying the flow properties it was found that angle of repose has value of $27.87^{\circ}$, which means powder will possess good flow property. The bulk density was found to be 0399 $\mathrm{g} / \mathrm{cm}^{3}$. Tapped density was observed as $0.477 \mathrm{~g} / \mathrm{cm}^{3}$. Carr's index was found to be $15.840 \%$ indicates a good flow ability of the powder blend. Hausner's ratio was found to be 1.194 . All the flow property parameters were studied thoroughly and all the properties compile the standard data, so we can say that solid dispersion show good flow property and data are shown in Table 3.

Table 3: Micrometrics properties of solid dispersion

\begin{tabular}{|c|c|c|c|c|}
\hline Angle of Repose ( ${ }^{\circ}$ & Bulk density $\left(\mathbf{g} / \mathbf{c m}^{3}\right)$ & $\begin{array}{c}\text { Tapped density } \\
\left(\mathbf{g} / \mathbf{c m}^{3}\right)\end{array}$ & $\begin{array}{c}\text { Carr's Index } \\
(\%)\end{array}$ & $\begin{array}{c}\text { Hausner's } \\
\text { ratio }\end{array}$ \\
\hline $27.87 \pm 1.18$ & $0.39 \pm 0.01$ & $0.47 \pm 0.04$ & $15.84 \pm 0.80$ & $1.19 \pm 0.10$ \\
\hline
\end{tabular}

Mean \pm SD; $n=3$ 


\section{Solubility study of the complex solid dispersion}

After complexation with PEG6000 and PVP K30, Ramipril exhibits remarkable enhancement solubility, increasing from $0.025 \mathrm{mg} / \mathrm{mL}$ to $7.54 \mathrm{mg} / \mathrm{mL}$ and $1.50 \mathrm{mg} / \mathrm{mL}$ respectively. While both complexes show significant Ramipril solubilization, comparison of the solubility's of the two complexes indicates that the solubility of the PEG6000 complex is several times higher than that of the PVP K30 complex. These solubilization results demonstrate that PEG6000 is a more efficient solubilizer than PVP K30, thus, PEG6000 was selected for further formulation and evaluation studies.

Table 4: Solubility of Pure drug and solid dispersion Phosphate Buffer pH 6.8

\begin{tabular}{|c|c|}
\hline Samples & Solubility $(\mathbf{m g} / \mathbf{m l})$ \\
\hline Pure drug & $0.025 \pm 0.006$ \\
\hline PEG 6000-solid dispersion & $7.54 \pm 0.021$ \\
\hline PVP K30- solid dispersion & $1.50 \pm 0.004$ \\
\hline
\end{tabular}

\section{Determination of Drug content}

The drug content of the complex formed was found to be $86.09 \pm 0.535 \%$.

\section{In-vitro dissolution studies}

Dissolution study shows that the dissolution rate of Ramipril has been enhanced largely. The drug release with PEG6000 was $77.42 \pm 0.398 \%$ in $0.1 \mathrm{~N} \mathrm{HCl}$ and of pure drug was 52.59 $\pm 0.481 \%$ and the drug release with PEG6000 was $79.40 \pm$ $0.292 \%$ in phosphate buffer pH 6.8 (PBS 6.8) and of pure drug was $58.78 \pm 0.382 \%$. Enhanced solubility and improved dissolution were obtained by solid dispersion in both PBS 6.8 and hydrochloric acid. Data are tabulated in Table 5.

Table 5: Percentage drug release of pure drug and Drug-PEG6000 solid dispersion complex in 0.1N $\mathrm{HCl}$ and phosphate buffer pH 6.8

\begin{tabular}{|c|c|c|c|c|}
\hline Time (hrs) & \multicolumn{2}{|c|}{ 0.1N HCl } & \multicolumn{2}{c|}{ Phosphate buffer pH 6.8 } \\
\hline & Pure Drug (\%) & Complex (\%) & Pure Drug (\%) & 0 \\
\hline 0 & 0 & 0 & $4.02 \pm 0.33$ & $15.31 \pm 0.95$ \\
\hline 0.25 & $1.40 \pm 0.39$ & $8.48 \pm 0.72$ & $8.17 \pm 0.48$ & $19.65 \pm 0.48$ \\
\hline 1 & $5.55 \pm 0.38$ & $13.78 \pm 0.38$ & $12.44 \pm 0.95$ & $22.72 \pm 0.58$ \\
\hline 2 & $8.48 \pm 0.48$ & $17.68 \pm 0.58$ & $15.51 \pm 0.57$ & $26.42 \pm 0.57$ \\
\hline 3 & $12.06 \pm 0.69$ & $22.91 \pm 0.29$ & $20.48 \pm 0.87$ & $31.53 \pm 0.77$ \\
\hline 4 & $15.76 \pm 0.48$ & $25.65 \pm 0.50$ & $25.14 \pm 0.77$ & $36.44 \pm 0.67$ \\
\hline 5 & $19.72 \pm 0.38$ & $31.21 \pm 0.19$ & $29.36 \pm 0.86$ & $42.06 \pm 0.96$ \\
\hline 6 & $24.06 \pm 0.22$ & $35.68 \pm 0.48$ & $33.63 \pm 0.58$ & $46.59 \pm 0.79$ \\
\hline 7 & $28.27 \pm 0.29$ & $38.61 \pm 0.61$ & $39.82 \pm 0.69$ & $51.14 \pm 0.39$ \\
\hline 8 & $31.27 \pm 0.67$ & $44.48 \pm 0.58$ & $45.76 \pm 0.76$ & $56.87 \pm 0.76$ \\
\hline 9 & $36.31 \pm 0.67$ & $49.78 \pm 0.57$ & $49.85 \pm 0.29$ & $60.06 \pm 0.72$ \\
\hline 10 & $41.23 \pm 0.48$ & $56.42 \pm 0.48$ & $53.55 \pm 0.96$ & $63.0 \pm 0.83$ \\
\hline 12 & $46.85 \pm 0.48$ & $62.48 \pm 0.58$ & $56.17 \pm 0.67$ & $72.95 \pm 0.66$ \\
\hline 24 & $50.29 \pm 0.48$ & $69.12 \pm 0.69$ & $58.78 \pm 0.38$ & $79.40 \pm 0.29$ \\
\hline
\end{tabular}

Mean \pm SD; $\mathrm{n}=3$ 


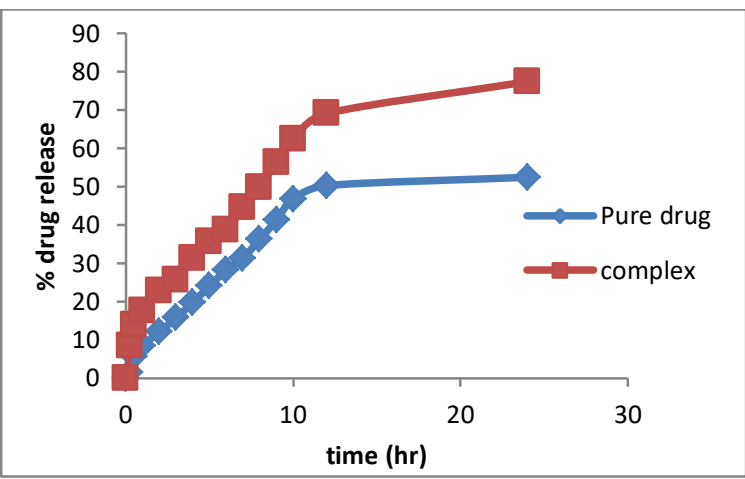

(a)

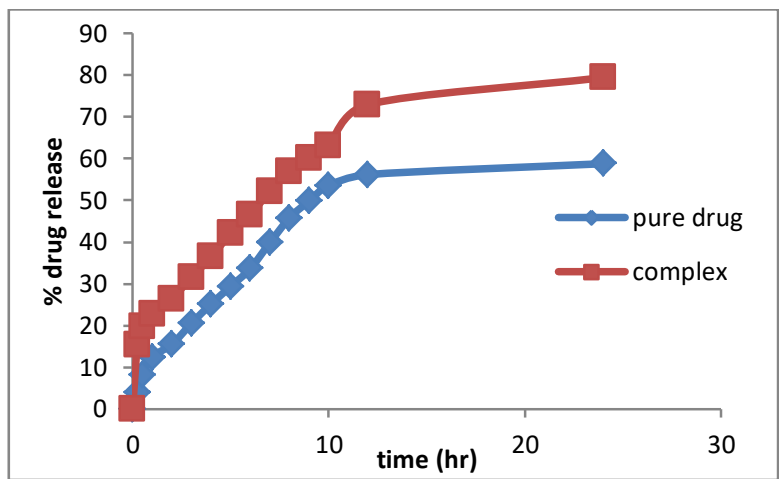

(b)

Figure 4: \% drug release of drug and its complex in $0.1 \mathrm{~N} \mathrm{HCl}$ (left) and Phosphate buffer pH 6.8 (right)

\section{Evaluation of tablets}

\section{Pre compression parameters}

All the pre-compression parameters were studied thoroughly and all the properties compile the standard data, so we can say that solid dispersion show good flow property and data are shown in Table 6.

Table 6: Pre compression parameters of Ramipril solid dispersion powder blend

\begin{tabular}{|c|c|c|c|c|c|}
\hline $\begin{array}{c}\text { Formulation } \\
\text { code }\end{array}$ & Angle of repose $\left.\mathbf{~}^{\mathbf{}} \mathbf{C}\right)$ & Bulk density $\left(\mathbf{g} / \mathbf{c m}^{3} \mathbf{)}\right.$ & $\begin{array}{c}\text { Tapped density } \\
\mathbf{( g / \mathbf { c m } ^ { 3 } )}\end{array}$ & Carr's index (\%) & Hausner's ratio \\
\hline F1 & $29.40 \pm 2.81$ & $0.354 \pm 0.003$ & $0.384 \pm 0.009$ & $7.78 \pm 1.61$ & $1.08 \pm 0.018$ \\
\hline F2 & $23.21 \pm 0.66$ & $0.312 \pm 0.005$ & $0.348 \pm 0.008$ & $10.38 \pm 0.915$ & $1.11 \pm 0.011$ \\
\hline F3 & $20.93 \pm 0.96$ & $0.375 \pm 0.014$ & $0.446 \pm 0.024$ & $15.79 \pm 1.50$ & $1.18 \pm 0.020$ \\
\hline F4 & $20.15 \pm 1.68$ & $0.306 \pm 0.012$ & $0.337 \pm 0.016$ & $9.14 \pm 0.959$ & $1.10 \pm 0.011$ \\
\hline F5 & $23.17 \pm 2.61$ & $0.327 \pm 0.001$ & $0.398 \pm 0.006$ & $18.00 \pm 1.82$ & $1.21 \pm 0.027$ \\
\hline F6 & $27.46 \pm 2.15$ & $0.336 \pm 0.005$ & $0.385 \pm 0.007$ & $12.81 \pm 1.21$ & $1.14 \pm 0.016$ \\
\hline F7 & $25.96 \pm 1.37$ & $0.316 \pm 0.008$ & $0.361 \pm 0.005$ & $12.43 \pm 1.15$ & $1.14 \pm 0.014$ \\
\hline F8 & $27.08 \pm 2.50$ & $0.321 \pm 0.002$ & $0.353 \pm 0.005$ & $9.17 \pm 1.54$ & $1.10 \pm 0.018$ \\
\hline F9 & $29.28 \pm 1.78$ & $0.301 \pm 0.002$ & $0.341 \pm 0.004$ & $11.61 \pm 1.40$ & $1.13 \pm 0.017$ \\
\hline
\end{tabular}

Mean \pm SD; $\mathrm{n}=3$

\section{Post Compression Parameters}

All formulation were subjected to post evaluation parameters viz. hardness, thickness, friability, weight variation, disintegration time, drug content and in-vitro dissolution studies. Each formulation passes all the parameters (Table 7). In-vitro dissolution studies was done in $1 \mathrm{~N} \mathrm{HCl}$ and phosphate buffer pH 6.8 buffer solution. In dissolution studies formulation $\mathrm{F} 4$ shows best result in both the dissolution medium. In $0.1 \mathrm{~N} \mathrm{HCl}$ it shows $86.55 \pm 0.69 \%$ and in phosphate buffer $\mathrm{pH} 6.8$ dissolution release was $92.55 \pm 0.67 \%$ in $30 \mathrm{~min}$ (Table 8,9 ). Therefore, we can say that phosphate buffer pH 6.8 shows better result as compared of $0.1 \mathrm{~N} \mathrm{HCl}$. The best formulation $\mathrm{F} 4$ were than compared with marketed formulation and data is shown in Table 10.

Table 7: Post-compression parameters of Ramipril Tablets

\begin{tabular}{|c|c|c|c|c|c|}
\hline $\begin{array}{c}\text { Formulation } \\
\text { code }\end{array}$ & $\begin{array}{l}\text { Hardness } \\
\left(\mathrm{kg} / \mathrm{cm}^{2}\right)\end{array}$ & Thickness (mm) & Friability (\%) & $\begin{array}{c}\text { Disintegration } \\
\text { time (sec) }\end{array}$ & Drug Content \\
\hline F1 & $4.10 \pm 0.560$ & $3.38 \pm 0.025$ & $0.634 \pm 0.073$ & $59.57 \pm 0.577$ & $98.3 \pm 0.436$ \\
\hline F2 & $4.01 \pm 0.025$ & $3.44 \pm 0.020$ & $0.468 \pm 0.094$ & $58.35 \pm 0.673$ & $98.2 \pm 0.410$ \\
\hline F3 & $4.04 \pm 0.011$ & $3.37 \pm 0.025$ & $0.580 \pm 0.066$ & $61.70 \pm 0.608$ & $99.6 \pm 0.071$ \\
\hline F4 & $4.08 \pm 0.075$ & $3.44 \pm 0.040$ & $0.345 \pm 0.064$ & $51.20 \pm 0.779$ & $99.2 \pm 0.089$ \\
\hline F5 & $4.42 \pm 0.015$ & $3.29 \pm 0.020$ & $0.569 \pm 0.101$ & $70.10 \pm 0.850$ & $98.3 \pm 0.121$ \\
\hline F6 & $4.41 \pm 0.015$ & $3.45 \pm 0.020$ & $0.452 \pm 0.106$ & $73.30 \pm 0.557$ & $97.4 \pm 0.520$ \\
\hline F7 & $4.82 \pm 0.015$ & $2.99 \pm 0.047$ & $0.323 \pm 0.072$ & $59.90 \pm 0.500$ & $97.8 \pm 0.520$ \\
\hline F8 & $4.75 \pm 0.017$ & $2.93 \pm 0.040$ & $0.659 \pm 0.129$ & $72.06 \pm 0.416$ & $97.2 \pm 0.263$ \\
\hline F9 & $4.03 \pm 0.015$ & $2.87 \pm 0.020$ & $0.655 \pm 0.046$ & $68.36 \pm 0.416$ & $96.3 \pm 0.473$ \\
\hline
\end{tabular}

Mean \pm SD; $\mathrm{n}=3$ 
Table 8: Percentage drug release of Ramipril Tablets in $0.1 \mathrm{~N} \mathrm{HCl}$

\begin{tabular}{|c|c|c|c|c|c|c|c|c|c|}
\hline $\begin{array}{l}\text { Time } \\
\text { (min) }\end{array}$ & F1 & F2 & F3 & F4 & F5 & F6 & F7 & F8 & F9 \\
\hline 0 & 0 & 0 & 0 & 0 & 0 & 0 & 0 & 0 & 0 \\
\hline 5 & $39.76 \pm 0.58$ & $44.61 \pm 0.38$ & $41.36 \pm 0.69$ & $46.46 \pm 0.29$ & $38.46 \pm 0.48$ & $45.66 \pm 0.39$ & $39.46 \pm 0.59$ & $38.36 \pm 0.49$ & $42.31 \pm 0.48$ \\
\hline 10 & $43.53 \pm 0.39$ & $47.93 \pm 0.79$ & $46.65 \pm 0.61$ & $51.76 \pm 0.48$ & $41.33 \pm 0.29$ & $55.96 \pm 0.48$ & $44.85 \pm 0.21$ & $42.25 \pm 0.61$ & $48.23 \pm 0.79$ \\
\hline 15 & $47.42 \pm 0.29$ & $51.51 \pm 0.33$ & $52.59 \pm 0.67$ & $62.44 \pm 0.76$ & $54.42 \pm 0.19$ & $56.94 \pm 0.76$ & $53.69 \pm 0.67$ & $48.59 \pm 0.77$ & $51.71 \pm 0.33$ \\
\hline 20 & $59.57 \pm 0.67$ & $55.27 \pm 0.67$ & $57.38 \pm 0.58$ & $70.78 \pm 0.58$ & $62.47 \pm 0.44$ & $68.48 \pm 0.18$ & $60.48 \pm 0.48$ & $57.18 \pm 0.18$ & $54.37 \pm 0.67$ \\
\hline 25 & $64.76 \pm 0.50$ & $60 \pm 0.94$ & $60.38 \pm 0.79$ & $82.59 \pm 0.58$ & $72.76 \pm 0.70$ & $78.59 \pm 0.98$ & $64.48 \pm 0.69$ & $63.78 \pm 0.59$ & $62.1 \pm 0.54$ \\
\hline 30 & $79.55 \pm 0.57$ & $68 \pm 0.38$ & $69.53 \pm 0.76$ & $86.55 \pm 0.69$ & $78.85 \pm 0.57$ & $83.35 \pm 0.29$ & $70.23 \pm 0.76$ & $68.23 \pm 0.46$ & $73.3 \pm 0.37$ \\
\hline
\end{tabular}

Mean \pm SD; $n=3$

Table 9: Percentage Drug Release of Ramipril Tablets in Phosphate Buffer pH 6.8

\begin{tabular}{|c|c|c|c|c|c|c|c|c|c|}
\hline $\begin{array}{l}\text { Time } \\
\text { (min) }\end{array}$ & F1 & F2 & F3 & F4 & F5 & F6 & F7 & F8 & F9 \\
\hline 0 & 0 & 0 & 0 & 0 & 0 & 0 & 0 & 0 & 0 \\
\hline 5 & $41.48 \pm 0.48$ & $48.51 \pm 0.86$ & $53.29 \pm 0.58$ & $49.65 \pm 0.58$ & $48.31 \pm 0.46$ & $44.48 \pm 0.48$ & $46.25 \pm 0.25$ & $42.24 \pm 0.68$ & $43.29 \pm 0.54$ \\
\hline 10 & $51.63 \pm 0.57$ & $50.29 \pm 0.48$ & $57.19 \pm 0.79$ & $54.57 \pm 0.76$ & $54.19 \pm 0.88$ & $48.63 \pm 0.57$ & $54.41 \pm 0.28$ & $54.19 \pm 0.59$ & $54.79 \pm 0.39$ \\
\hline 15 & $64.51 \pm 0.86$ & $59.06 \pm 0.22$ & $61.72 \pm 0.39$ & $61.59 \pm 0.79$ & $64.06 \pm 0.22$ & $54.51 \pm 0.86$ & $59.46 \pm 0.52$ & $58.42 \pm 0.39$ & $61.12 \pm 0.28$ \\
\hline 20 & $68.46 \pm 0.61$ & $66.36 \pm 0.57$ & $66.44 \pm 0.57$ & $76.72 \pm 0.77$ & $72.56 \pm 0.67$ & $68.46 \pm 0.61$ & $64.41 \pm 0.23$ & $62.44 \pm 0.47$ & $69.34 \pm 0.27$ \\
\hline 25 & $70.51 \pm 0.58$ & $74.59 \pm 0.39$ & $69.31 \pm 0.95$ & $84.31 \pm 0.79$ & $79.49 \pm 0.29$ & $73.51 \pm 0.58$ & $72.19 \pm 045$ & $68.41 \pm 0.45$ & $78.41 \pm 0.25$ \\
\hline 30 & $83.46 \pm 0.39$ & $85.12 \pm 0.87$ & $72.44 \pm 0.77$ & $92.55 \pm 0.67$ & $85.42 \pm 0.17$ & $77.46 \pm 0.39$ & $81.12 \pm 0.74$ & $79.14 \pm 0.14$ & $84.34 \pm 0.51$ \\
\hline
\end{tabular}

Mean \pm SD; $\mathrm{n}=3$

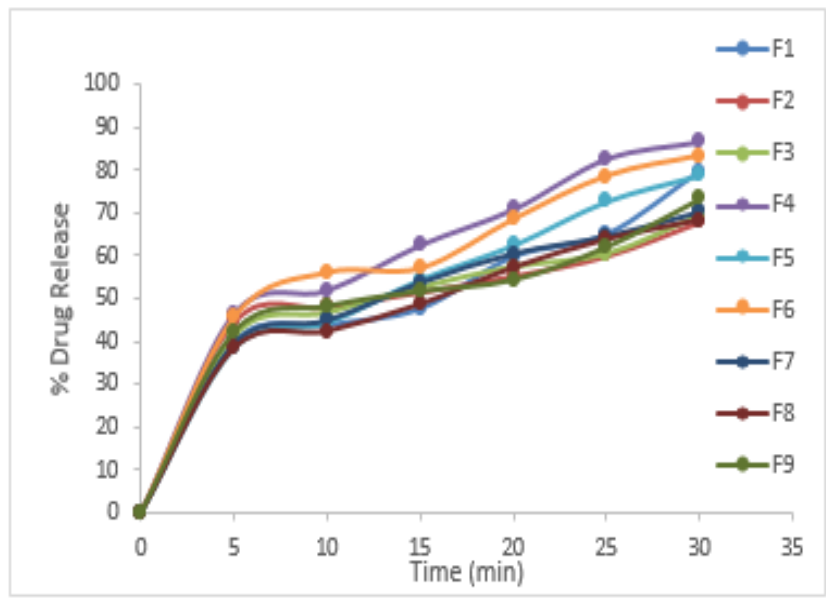

(a)

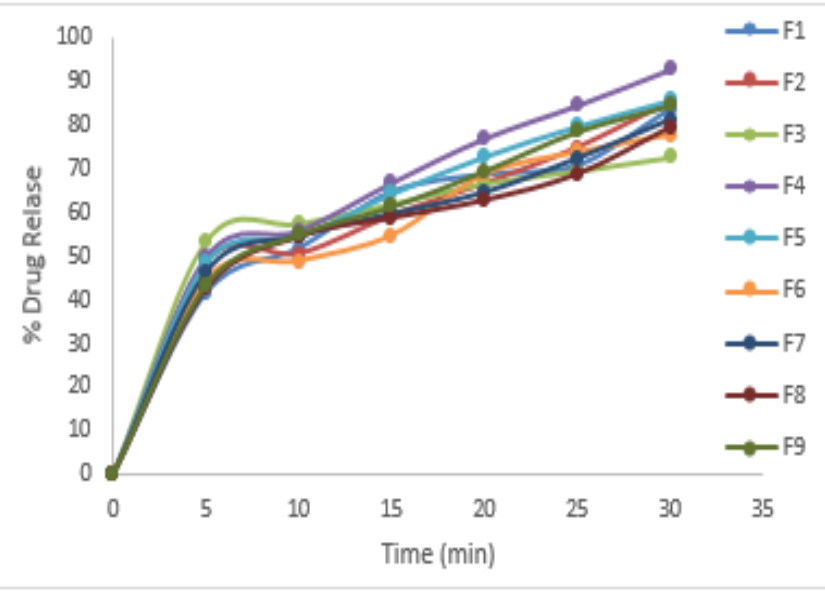

(b)

Figure 5: Percent drug release of all formulation (a) 0.1 N HCl (b) Phosphate buffer pH 6.8

Table 10: Percentage drug release of optimized formulation (F4) with marketed formulation in phosphate buffer pH 6.8

\begin{tabular}{|c|c|c|}
\hline Time (min) & $\begin{array}{c}\text { Formulation } \\
\text { F4 }\end{array}$ & $\begin{array}{c}\text { Marketed } \\
\text { Formulation }\end{array}$ \\
\hline 0 & 0 & 0 \\
\hline 5 & $49.65 \pm 0.58$ & $48.74 \pm 0.72$ \\
\hline 10 & $54.57 \pm 0.76$ & $55.53 \pm 0.48$ \\
\hline 15 & $66.59 \pm 0.79$ & $63.46 \pm 0.77$ \\
\hline 20 & $79.72 \pm 0.77$ & $77.36 \pm 0.29$ \\
\hline 25 & $90.31 \pm 0.79$ & $84.82 \pm 0.57$ \\
\hline 30 & $92.45 \pm 0.67$ & $88.45 \pm 0.98$ \\
\hline
\end{tabular}

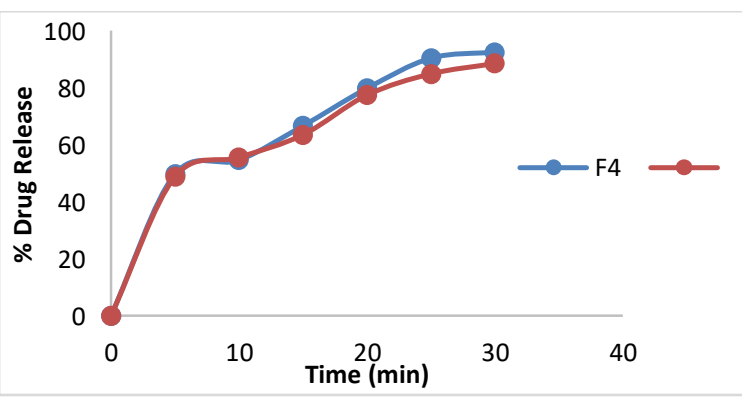

Figure 6: Percent drug release of optimized formulation (F4) with marketed formulation in phosphate buffer $\mathrm{pH}$ 6.8 


\section{CONCLUSION}

The present work was based on the enhancement of the dissolution rate of Ramipril tablet by solid dispersion technique. Solid dispersion complex was prepared with two different carriers PEG 6000 and PVP K30. Phase solubility study of the PEG6000- complex had shown greater stability constant. FTIR studies of PEG 6000 with complex showed no interaction. The micromeretic properties of the solid dispersion was studied and showed good flow properties. Nine formulations were developed and pre-compression parameters were studied which had shown good flow property and compiled the standard data. In the post compression parameters, all formulation shows good results. Formulation F4 showed $92.55 \pm 0.67 \%$ drug release in phosphate buffer $\mathrm{pH} 6.8$ and $86.55 \pm 0.69 \%$ in $0.1 \mathrm{~N} \mathrm{HCl}$ as compared to other formulation. The best formulation were compared with marketed formulation and shows greater result i.e. $92.45 \pm 0.67 \%$ drug release in $30 \mathrm{~min}$. Therefore, Ramipril solid dispersion tablets have shown maximum drug release, and can be more efficacious for improving oral bioavailability of Ramipril.

\section{CONFLICT OF INTEREST}

The authors declare no conflict of interest

\section{ACKNOWLEDGEMENT}

The Author is highly grateful to the Dr. R. K Abhilashi, Chairman Abhilashi Group of Institutions, Mandi, India for providing necessary facilities to carry out the research.

\section{REFERENCES}

1. Sekiguchi K. Studies on Absorption of Eutectic Mixture. A Comparison of the Behavior of Eutectic Mixture of Sulfathiazole and that of Ordinary Sulfathiazole in Man. Chem Pharm Bull. 1961: 866-872.

2. Manogna K, Nagaveni P, Thyagaraju K. Enhancement of solubility of poorly soluble drugs by solid dispersion: An overview. Ind. Journal of Pharmaceutical and Biological Research. 2017; 5:17-23.

3. Fischer, Jnos Ganellin, C Robin. Analogue-based Drug Discovery. John Wiley \& amp; Sons. 2006; 469.
4. British national formulary: BNF. Pharmaceutical Press. 2018; 76:172-173.

5. Hilal Dandan R, Goodman Gilmans. The Pharmacological Basis of Therapeutics. McGraw-Hill Education. 2018; 13:26.

6. Frampton JE, Peters DH. Ramipril An updated review of its therapeutic use in essential hypertension and heart failure. Drugs. 1995; 49(3):440-66.

7. Ali J, Khar R, Ahuja A. A textbook of dosage form design. Birla publications Pvt Ltd, Delhi. 3rd edition. 2008; 100-107.

8. Pandey A, Rath B, AK D. Pharmaceutical Preformulation Studies with Special Emphasis on Excipients Compatibility. Chem Inform. 2012; 43(23): 20-5.

9. KP Sampath Kumar, Debjit Bhowmik, Rajnish Kumar Singh. Formulation and evaluation of Ramipril transdermal patch. IAJPR. 2014; 4(4):1850-1856

10. George SJ, Vasudevan DT. Studies on the preparation, characterization and solubility of 2-HP- $\beta$-cyclodextrinMeclizine $\mathrm{HCl}$ inclusion complexes. JYP. 2012; 4(4):220-227.

11. Peixiao T, Shanshan Li, Wang L, Yang H, Yan J, Hui L. Inclusion complexes of chlorzoxazone with $\beta$ - and hydroxypropyl- $\beta$ cyclodextrin: Characterization, dissolution,and cytotoxicity. Carbo. Poly 131. 2015:297-305

12. B Venkateswara Reddy, K Navaneetha. Formulation and evaluation of sustain release tablets of Ramipril. Pharmatutor. 2014; 2(7):110-119.

13. Swati CJ, Yashwant TD, Bhanudas SK. Solubility enhancement and formulation of buccal patches of ramipril cyclodextrin complex. Asian J Pharm Clin Res. 2013; 6(2):83-90.

14. Venugopal P, Gnanaprakash K, Kumar B, Gobinath M, Narendra RB. Development of formulation and evaluation of Ramipril porous tablet by sublimation technique. IJB. 2014; 5(4):258-264.

15. Bhusnure OG, Kazi P, Gholve SB, S, Thonte SS, Sangshetti JN. Formulation and Evaluation of Fast Disintegrating Tables of Nifedipine by QbD Approach. IJPPR. 2015; 4(3):198-229.

16. Pradhan R, Tran TH, Choi JY, Choi IS, Choi HG, Yong CS, et al. Development of a rebamipide solid dispersion system with improved dissolution and oral bioavailability. Arch. Pharm. Res. 2014: 1-12.

17. Jumbarathi SK, Chandrasekhara RB, Kavati R, Vanitha PK. Formulation and evaluation of bilayer floating tablets of atorvastatin and ramipril. IAJPS. 2014; 1(2):98-106.

18. Manjil P, Tekade A, Gattani S, Surana S. Solubility enhancement of lovastatin by modified locust bean gum using solid dispersion techniques. Pharm Sci Tech. 2008; 9(4):1262-1269. 